Research Paper

\title{
Efficacy of epidermal growth factor receptor-tyrosine kinase inhibitors for lung squamous carcinomas harboring EGFR mutation: A multicenter study and pooled analysis of published reports
}

\author{
Yongmei Liu ${ }^{1, *}$, Yan Zhang ${ }^{1, *}$, Li Zhang', Bin Liu ${ }^{3}$, Yongsheng Wang ${ }^{1}$, Xiaojuan \\ Zhou ${ }^{1}$, Yanying $\mathrm{Li}^{1}$, Qian Zhao ${ }^{4}$, Youling Gong ${ }^{1}$, Lin Zhou ${ }^{1}$, Jiang Zhu ${ }^{1}$, Zhenyu \\ Ding ${ }^{1}$, Jin Wang ${ }^{1}$, Feng Peng ${ }^{1}$, Meijuan Huang ${ }^{1}$, Lu Li ${ }^{1}$, Li Ren ${ }^{1}$ and You Lu ${ }^{1}$ \\ ${ }^{1}$ Department of Thoracic Oncology, Cancer Center and State Key Laboratory of Biotherapy, West China Hospital, Sichuan \\ University, Chengdu, China \\ ${ }^{2}$ Department of Medical Oncology, Sun Yat-Sen University Cancer Center, Guangzhou, China \\ ${ }^{3}$ Pulmonary Tumor Ward, Sichuan Cancer Hospital, Chengdu, China \\ ${ }^{4}$ West China School of Medicine, Sichuan University, Chengdu, China \\ *These authors contributed equally to this work
}

Correspondence to: You Lu, email: radyoulu@hotmail.com

Keywords: squamous cell carcinoma, EGFR mutation, epidermal growth factor receptor-tyrosine kinase inhibitor

Received: February 14, 2017

Accepted: May 01, 2017

Published: May 17, 2017

Copyright: Liu et al. This is an open-access article distributed under the terms of the Creative Commons Attribution License 3.0 (CC BY 3.0 ), which permits unrestricted use, distribution, and reproduction in any medium, provided the original author and source are credited.

\section{ABSTRACT}

Epidermal growth factor receptor (EGFR) mutations are common in lung adenocarcinoma (ADC) but rare in squamous cell carcinoma (SQC). The efficacy of EGFR-tyrosine kinase inhibitors (EGFR-TKIs) for SQC with EGFR mutations is unclear. The aim of this study was to evaluate the efficacy of EGFR-TKIs for these patients. We performed a retrospective matched-pair case-control study from 3 cancer centers, including 44 SQC and 44 ADC patients with EGFR mutation who were treated with EGFR-TKI. Subsequently, we performed a pooled analysis on the efficacy of EGFR-TKIs for EGFR-mutant SQC in 115 patients, including 71 patients selected from 25 published reports. In our multicenter study, EGFR-mutant SQC and ADC patients had similar objective response rate (ORR) $(43.2 \%$ vs. $54.5 \%, p=0.290)$, but SQC patients had lower disease control rate (DCR) $(71.3 \%$ vs. $100 \%, p=0.001)$, significant shorter median progression free survival (PFS) (5.1 vs. 13.0 months, $p=0.000$ ) and median overall survival (OS) (17.2 vs. 23.6 months, $p=0.027)$. In pooled analysis, the ORR, DCR, PFS and OS of SQC patients were 39.1\%, 71.3\%, 5.6 months and 15.0 months, respectively. Performance status was the only independent predictor of PFS and erlotinib treatment was associated with a better survival. In conclusion, EGFR-TKI was less effective in EGFR-mutant SQC than in ADC but still has clinical benefit for SQC patients. Further study is need to evaluate the using of EGFR-TKIs in these SQC patients.

\section{INTRODUCTION}

Epidermal growth factor receptor-tyrosine kinase inhibitors (EGFR-TKIs) are currently recommended as the standard first line treatment for non-small cell lung cancer (NSCLC) harboring EGFR-sensitive mutations. The majority of clinical data regarding EGFR-TKIs in EGFR-mutant population are derived from lung adenocarcinoma (ADC).
The percentage of EGFR mutations in lung squamous cell carcinoma (SQC) is only about $10 \%$ in persons of Asian descent [1] and $<5 \%$ in western countries [2]. Our literature review only identified small case series studies and case reports about the sensitivity of EGFR-TKI in SQC with EGFR mutation in the literature. The objective response rates (ORR), disease control rates (DCR) and median progression free survival rates (PFS) in 
these studies were $25.0-26.7 \%, 66.7-71.0 \%$ and $1.4-6.3$ months, respectively [3-5]. EGFR-TKI seems to be less effective in SQC than in ADC and the role of EGFR-TKI in EGFR-mutant SQC remains to be debated.

We therefore performed a matched-pair case-control study retrospectively to investigate the different efficacy of EGFR-TKI in EGFR-mutant SQC and ADC patients from 3 cancer centers. Subsequently, a pooled analysis that included our own data and data obtained from previous studies at other institutions was carried out to evaluate the role of EGFR-TKIs in EGFR-mutant SQC, which represents the largest study to our knowledge of this patient cohort.

\section{RESULTS}

\section{Patient characteristics}

The initial matched-pair case-control study included 88 NSCLC patients from 3 cancer centers (44 SQC and 44 ADC). Among them, 52 patients were male, 46 patients were non-smokers and 62 patients had an Eastern Cooperative Oncology Group performance status (ECOG PS) of 0-1. The median age was 56 years (range: 32-80). Patient characteristics are shown in Table 1. Each group included 28 patients with a 19-DEL mutation, 15 with a L858R mutation and 1 with a G719X and S768I mutation simultaneously; 19 patients received EGFR-TKIs as first line treatment and 25 patients had prior chemotherapy; 26 patients received gefitinib, 14 received erlotinib, and 4 received icotinib.

The subsequent pooled analysis included 115 EGFRmutant lung SQC patients treated with EGFR-TKIs. Seventyone patients were selected from 25 reports [3, 6-29]; 55 patients $(71.8 \%)$ in 19 of these reports were from East Asian countries. Definitive data of age, gender, smoking history, PS, status of EGFR mutation and drugs of EGFRTKIs treatment could be extracted in 38(53.5\%), 56(78.9\%), $51(71.8 \%), 15(21.1 \%), 59(83.1 \%)$ and $42(59.2 \%)$ of the 71 patients, respectively. Patient characteristics for this cohort are summarized in Table 2. The median age was 61.5 years. Gender, smoking history, and PS were: male (63/100, $63.0 \%$ ), female $(37 / 100,37.0 \%)$; never smoker (44/95, $46.3 \%)$, smoker (51/95, 53.7\%); PS < 2 (42/59, 71.2\%), PS $\geq 2(17 / 59,28.8 \%)$. There were 55 patients $(55 / 103,53.4 \%)$ with 19-DEL mutations, 31 patients $(31 / 103,30.1 \%)$ with L858R mutations and 17 patients $(17 / 103,16.5 \%)$ with other mutations. Fifty-eight $(58 / 86,67.4 \%)$ patients received gefitinib, 24 patients $(24 / 86,27.9 \%)$ received erlotinib and 4 patients $(4 / 86,4.7 \%)$ received icotinib. Twenty-seven patients $(27 / 82,32.9 \%)$ were treated with TKIs as first line treatment and 55 patients $(55 / 82,67.1 \%)$ had prior chemotherapy.

\section{Response and survival}

In the matched-pair case-control study, the median follow-up time for all the 88 patients was 41.1 months (range, 0.5-61.0 months) upto the study closing date of December 30, 2015. For SQC patients 19 had partial responses (PR), 15 had stable disease (SD) and 10 had progressive disease (PD) after EGFR-TKI treatment, which resulted in ORR of $43.2 \%$ and DCR $77.3 \%$. For ADC patients, ORR was $54.5 \%$ and DCR was $100 \%$, including $24 \mathrm{PR}$ and $20 \mathrm{SD}$. There was no significant difference of ORR between SQC and ADC groups (43.2\% versus $54.5 \%, P=0.290)$, but SQC group had lower DCR than ADC group $(77.3 \%$ vs. $100 \%, P=0.001)$. By the time of the final analysis, 9 patients had not experienced progression and 20 patients were still alive in both SQC and ADC group. The median PFS of all the patients was 10.7 months (95\% CI: 8.38-13.03). SQC group had significant shorter PFS than ADC group (5.1 vs. 13.0 months, $p=0.000$ ) (Figure 1). The median OS of all the patients was 22.7 months (95\% CI: 20.53- 24.87). The OS of SQC group and ADC group had statistical significant difference (17.2 vs. 23.6 months, $p=0.027$ ) (Figure 2).

In the pooled analysis, tumor response was identified in 71 patients from the published reports. The ORR and DCR were $39.1 \%$ and $71.3 \%$, respectively, of all the 115 SQC patients. PFS was identified in 28 patients from the published reports. The PFS analysis was performed in 72 SQC patients. The median PFS of all the patients was 5.6 months (95\% CI: 3.93-7.27 months). Better PS (ECOG 0-1) was associated with better PFS both in univariate and multivariate analysis (Table 3). OS was extracted in 26 patients from the reports. The OS analysis was performed in 70 SQC patients. The median OS of all the patients was 15.0 months (95\% CI: 8.15-21.85 months). The patients treated with erlotinib had longer OS than those treated with gefitinib both in univariate and multivariate analysis (Table 4).

\section{DISCUSSION}

In this study, we investigated the efficacy of EGFRTKI treatment in lung SQC harboring EGFR mutation. We found that the ORR, DCR, PFS and OS of EGFR-mutated lung SQC treated with EGFR-TKI were 39.1\%, 71.3\%, 5.6 months and 15.0 months, respectively.

In our multicenter matched-pair case-control study, SQC patients had significant lower DCR, shorter PFS and OS than ADC patients. Although the mechanism behind the efficacy difference between ADC and SQC is unclear, there is now evidence from previous studies, including the TCGA study, revealing a number of genomic differences between ADC and SQC [30]. Gene amplifications of $3 \mathrm{q}$ including SOX2, TP63, PIK3CA, and EPHB3 were observed in as many as $86 \%$ of SQC samples but only $21 \%$ of adenocarcinoma samples [31]. Allelic losses [32] or hypermethylations [33] on the $3 p$ region has been observed more frequently in tumors with a squamous histology compared with adenocarcinoma, involving some tumor suppressor genes such as RASSF1A, FUS1, 


\begin{tabular}{|c|c|c|c|c|}
\hline & \multicolumn{2}{|c|}{ SQC } & \multicolumn{2}{|c|}{ ADC } \\
\hline & $n=44$ & Percent (\%) & $n=44$ & Percent (\%) \\
\hline \multicolumn{5}{|l|}{ Gender } \\
\hline Male & 26 & 59.1 & 26 & 59.1 \\
\hline Female & 18 & 40.9 & 18 & 40.9 \\
\hline \multicolumn{5}{|l|}{ Age(years) } \\
\hline$\geq 70$ & 38 & 86.4 & 38 & 86.4 \\
\hline$<70$ & 6 & 13.6 & 6 & 13.6 \\
\hline \multicolumn{5}{|l|}{ ECOG PS } \\
\hline$<2$ & 31 & 68.9 & 31 & 68.9 \\
\hline$\geq 2$ & 14 & 31.1 & 14 & 31.1 \\
\hline \multicolumn{5}{|l|}{ Smoking status } \\
\hline Smoker(current/former) & 23 & 52.3 & 23 & 52.3 \\
\hline Non-smoker(never) & 21 & 47.7 & 21 & 47.7 \\
\hline \multicolumn{5}{|l|}{ EGFR mutation type } \\
\hline 19-DEL & 28 & 63.6 & 28 & 63.6 \\
\hline L858R & 15 & 34.1 & 15 & 34.1 \\
\hline G719X/S768I & 1 & 2.3 & 1 & 2.3 \\
\hline \multicolumn{5}{|l|}{ Prior chemotherapy } \\
\hline 0 & 19 & 43.2 & 19 & 43.2 \\
\hline$\geq 1$ & 25 & 56.8 & 25 & 56.8 \\
\hline \multicolumn{5}{|l|}{ EGFR-TKI treatment } \\
\hline Gefitinib & 26 & 59.1 & 26 & 59.1 \\
\hline Erlotinib & 14 & 31.8 & 14 & 31.8 \\
\hline Icotinib & 4 & 9.1 & 4 & 9.1 \\
\hline
\end{tabular}

SQC, squamous cell carcinoma; ADC, adenocarcinoma; ECOG PS, Eastern Cooperative Oncology Group performance status; EGFR, epidermal growth factor receptor; TKI, tyrosine kinase inhibitor.

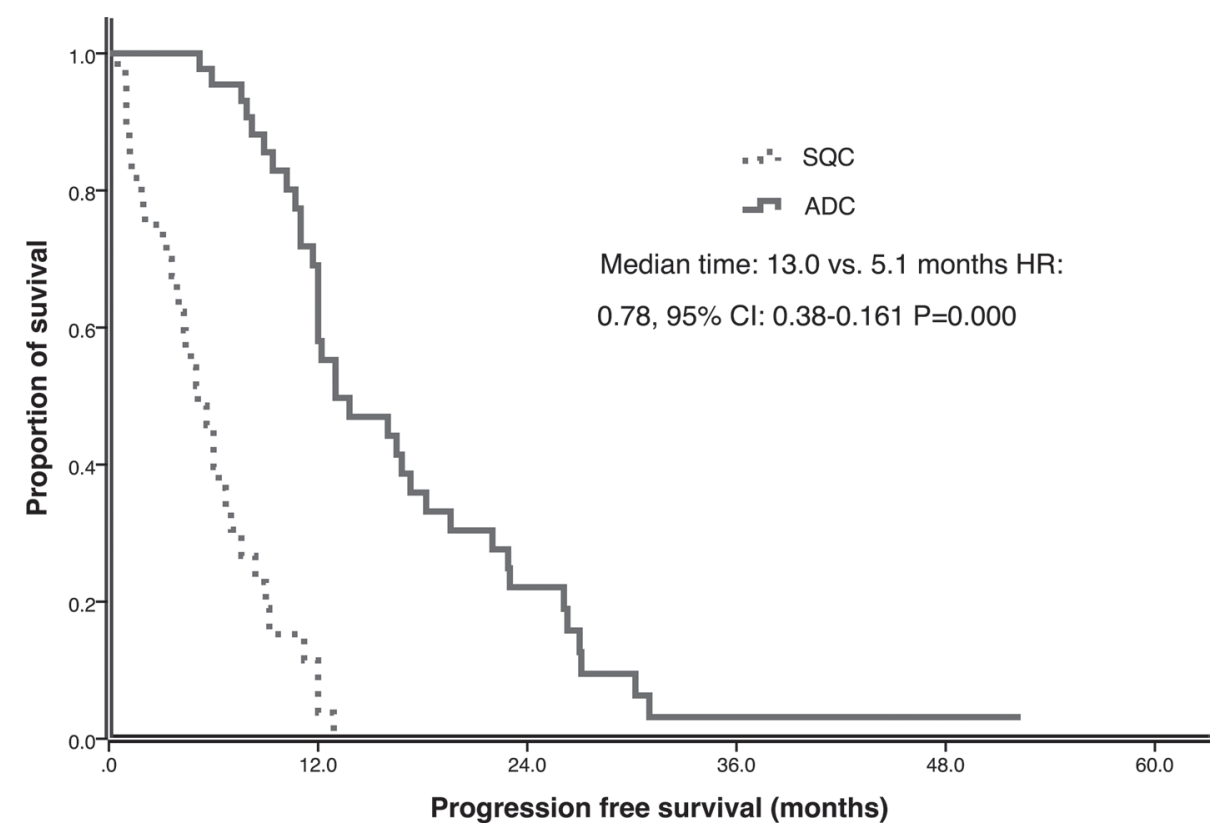

Figure 1: Progression free survival (PFS) of ADC and SQC in multicenter study. 
Table 2: Characteristics of the squamous cell carcinoma patients included in the pooled analysis $(n=115)$

\begin{tabular}{|c|c|c|}
\hline & $n$ & $\%$ \\
\hline Gender & 100 & \\
\hline Male & 63 & 63.0 \\
\hline Female & 36 & 37.0 \\
\hline Age(years) & 82 & \\
\hline Median & 61.5 & \\
\hline Range & $29-82$ & \\
\hline ECOG PS & 59 & \\
\hline$<2$ & 42 & 71.2 \\
\hline$\geq 2$ & 17 & 28.8 \\
\hline Smoking status & 95 & \\
\hline Smoker(current/former) & 51 & 53.7 \\
\hline Non-smoker(never) & 44 & 46.3 \\
\hline EGFR mutation type & 103 & \\
\hline 19-DEL & 55 & 53.4 \\
\hline L858R & 31 & 30.1 \\
\hline Other mutations & 17 & 16.5 \\
\hline Prior chemotherapy & 82 & \\
\hline 0 & 27 & 32.9 \\
\hline$\geq 1$ & 55 & 67.1 \\
\hline EGFR-TKI treatment & 86 & \\
\hline Gefitinib & 58 & 67.4 \\
\hline Erlotinib & 24 & 27.9 \\
\hline Icotinib & 4 & 4.7 \\
\hline Efficacy of EGFR-TKIs & 115 & \\
\hline $\mathrm{CR} / \mathrm{PR}$ & 45 & 39.1 \\
\hline SD & 37 & 32.2 \\
\hline PD & 33 & 28.7 \\
\hline
\end{tabular}

ECOG PS, Eastern Cooperative Oncology Group performance status; EGFR, epidermal growth factor receptor; TKI, tyrosine kinase inhibitor.

VHL, and FHIT. Meanwhile activations of other signaling pathways, such as ERBB2 [34] and PIK3CA [35, 36] may mediate resistance of lung cancers to EGFR-targeting therapies. We theorize that multiple signaling pathways are activated in the development and progression of lung SQC, while ADC may depend on a key pathway, such as EGFR, ALK or ROS-1. Accordingly, the efficacy is inferior in SQC patients when therapy to block a single pathway is used. However, we feel that the utility of EGFR-TKI in SQC should be studied further.

We found that SQC patients treated with EGFR-TKI had the similar ORR to ADC patients. Approximately one third of the EGFR-mutant SQC patients obtained a PFS longer than 6 months and an OS longer than 1 year which may be due to the efficacy of EGFR-TKIs. Some EGFRmutant SQC could benefit from EGFR-TKI treatment and EGFR-TKI is an important intervention for these patients.
Further study is needed to identify these patients that may benefit.

The incidence of EGFR mutations in lung SQC may differ in Asian and non-Asian populations. Previous reports revealed that the incidence of EGFR mutations in western populations is low, ranging from $0 \%$ to $3.6 \%$ $[37,38]$. However, the frequency of EGFR mutation is much higher in Asian populations $[1,3,5]$. The incidence of SQC harboring sensitive EGFR mutation was 13.3\% $(63 / 249)$ in Japan [3] and $17.8 \%(109 / 614)$ in another study from Chin a [5]. In our center, the EGFR-mutant incidence of lung SQC was $6.1 \%$ (22/359). Therefore, we consider routine EGFR mutation testing for all Asian lung SQC patients.

This study is a retrospective multiple center and comprehensive review of the published literature. The validation of the results relies on higher level evidence, 
Table 3: Association between clinical factors and the PFS

\begin{tabular}{|c|c|c|c|}
\hline & PFS (months) & Univariate analysis, $P^{a}$ & Multivariate analysis, $\mathrm{P}^{\mathrm{b}}$ \\
\hline Gender & & 0.327 & \\
\hline Male & 6.3 & & \\
\hline Female & 5.0 & & \\
\hline Smoking status & & 0.498 & \\
\hline Smoker(current/former) & 6.3 & & \\
\hline Non-smoker(never) & 5.1 & & \\
\hline EGFR mutation type & & 0.217 & \\
\hline 19-DEL & 5.0 & & \\
\hline L858R & 7.0 & & \\
\hline ECOG PS & & 0.000 & 0.001 (HR:4.141, 95\%CI: $1.854-9.248)$ \\
\hline$<2$ & 6.7 & & \\
\hline$\geq 2$ & 3.1 & & \\
\hline Prior chemotherapy & & 0.820 & \\
\hline 0 & 6.0 & & \\
\hline$\geq 1$ & 5.0 & & \\
\hline EGFR-TKI treatment & & 0.116 & \\
\hline Gefitinib & 4.4 & & \\
\hline Erlotinib & 7.0 & & \\
\hline
\end{tabular}

ECOG PS, Eastern Cooperative Oncology Group performance status; EGFR, epidermal growth factor receptor; TKI, tyrosine kinase inhibitor; PFS, median progression free survival; ${ }^{a}$ Log-rank test. ${ }^{b}$ Cox regression test

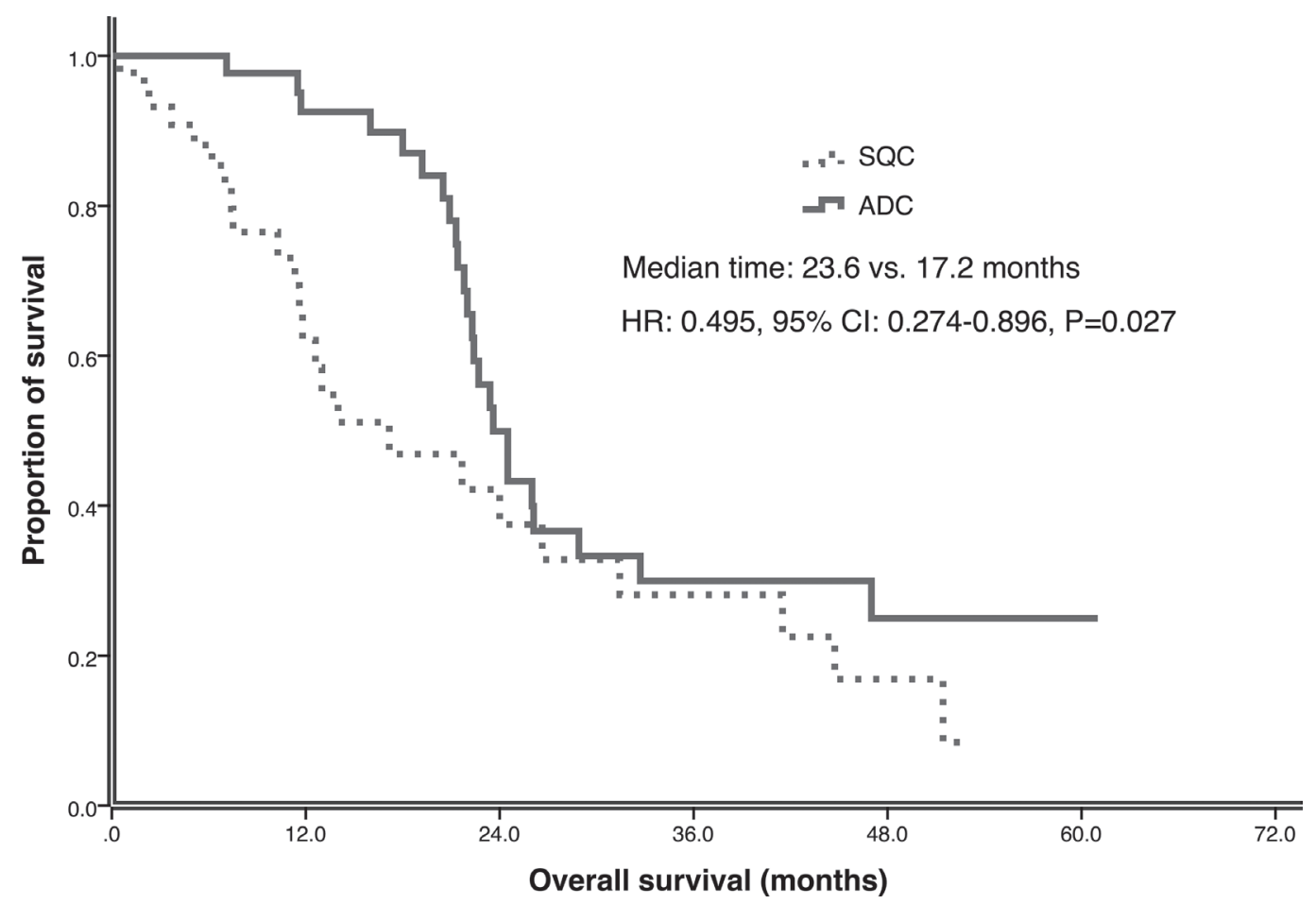

Figure 2: Overall survival (OS) of ADC and SQC in multicenter study. 


\begin{tabular}{|c|c|c|c|}
\hline & OS (months) & Univariate analysis, $P^{a}$ & Multivariate analysis, $\mathbf{P}^{b}$ \\
\hline Gender & & 0.667 & \\
\hline Male & 17.2 & & \\
\hline Female & 15.0 & & \\
\hline Smoking status & & 0.481 & \\
\hline Smoker(current/former) & 17.2 & & \\
\hline Non-smoker(never) & 14.0 & & \\
\hline EGFR mutation type & & 0.905 & \\
\hline 19-DEL & 14.0 & & \\
\hline L858R & 24.0 & & \\
\hline ECOG PS & & 0.067 & \\
\hline$<2$ & 17.2 & & \\
\hline$\geq 2$ & 6.2 & & \\
\hline Prior chemotherapy & & 0.363 & \\
\hline 0 & 12.6 & & \\
\hline$\geq 1$ & 19.3 & & \\
\hline EGFR-TKI treatment & & 0.047 & 0.025 (HR: $0.391,95 \% \mathrm{CI}: 0.172-0.887)$ \\
\hline Erlotinib & 24.0 & & \\
\hline Gefitinib & 11.6 & & \\
\hline
\end{tabular}

ECOG PS, Eastern Cooperative Oncology Group performance status; EGFR, epidermal growth factor receptor; TKI, tyrosine kinase inhibitor; OS, median overall survival; ${ }^{\mathrm{L}} \mathrm{Oog}$-rank test. ${ }^{\mathrm{b}} \mathrm{Cox}$ regression test.

such as randomized controlled trials. Although this study includes all available data we identified in the literature, the sample size is still insufficient. Large sample studies would help generate more robust conclusions.

In conclusion, EGFR-TKI was less effective in EGFRmutant SQC than in ADC but still has clinical benefit for some SQC patients. We present the largest pooled analysis to identify the clinical profiles of EGFR-TKI application for EGFR-mutant SQC, which may provide valuable information for treatment selection.

\section{MATERIALS AND METHODS}

\section{Patients}

From January 2004 to October 2015, 44 EGFRmutant SQC patients treated with EGFR-TKI (gefitinib $250 \mathrm{mg}$ /day, erlotinib $150 \mathrm{mg}$ /day or icotinib $125 \mathrm{mg}$ tid) were selected from 3 cancer centers including the cancer centers of West China Hospital, Sichuan University, Sun Yat-sen University Cancer Center and Cancer Hospital of Sichuan Province, China. The patients were diagnosed by bronchofiberscope or percutaneous lung biopsy. The pathological diagnosis was confirmed by light microscopy and immunohistochemistry (IHC) and verified by stains for P40, thyroid transcription factor (TTF)-1 and Napsin A (negative, positive, and negative, respectively). EGFR mutations were identified by real-time Amplification
Refractory Mutation System (ARMS) quantitative PCR analysis using AmoyDxTM EGFR Mutation Detection Kit (Amoy Diagnostics Co., LTD, China) and EGFR Scorpion ARMS Kit (DxS Ltd, Manchester, UK). All patients have the confirmed status of EGFR mutation.

EGFR-mutant ADC patients were pair matched to selected SQC patients from our lung cancer database according to seven variables: gender (male, female); age ( $<70$ years, $\geq 70$ years); smoking history (non-smokers, current or former smokers); ECOG PS $(<2, \geq 2)$; status of EGFR mutation (19-DEL, L858R, G719X/S768I); drugs of EGFR-TKI (gefitinib, erlotinib, icotinib) and prior chemotherapy $(0, \geq 1)$. Clinical data of each patients was well recorded.

Tumor response was determined by the Response Evaluation Criteria in Solid Tumors (RECIST) version 1.1 , including complete response (CR), partial response (PR), stable disease (SD), and progressive disease (PD). The treatment response was evaluated 1 month after the initiation of EGFR-TKI therapy and then every 2 months. This retrospective analysis was approved by the Institutional Review Board of the above stated hospitals and signed consent was obtained from each patient for the use of tissue in molecular analysis.

In order to further investigate the efficacy of EGFRTKI for EGFR-mutant lung SQC, we performed a systematic search of the PUBMED database to identify all clinical trials and case reports that contained EGFR-mutant SQC patients 
treated with EGFR-TKI. The search strategy included articles from April 2004 to November 2015 indexed under the subject headings EGFR, mutation, and lung cancer. We did not restrict the search on the type of publication or periodical. All published reports that described the efficacy of EGFR-TKIs for EGFR-mutant SQC were selected. From the author's publications, we extracted the data of the SQC patients. If the data important for us to analyze was not shown in the article, we wrote to the authors asking for help to obtain the data. 71 patients were identified by the above strategy.

\section{Statistical analysis}

PFS was calculated from the date of initiation of EGFR-TKIs to the time of disease progression. Overall survival (OS) was calculated from the time of beginning receiving EGFR-TKIs until the date of death. Survival curves were estimated by the Kaplan-Meier method and compared by the log-rank test. Multivariate analysis was performed using Cox regression test. Comparison of the qualitative data was done by Pearson $\chi^{2}$ or the Fisher exact test. $P$ values $<0.05$ was considered statistically significant. All statistical analyses were performed with SPSS 22.0.

\section{ACKNOWLEDGMENTS AND FUNDING}

We thank Dr. Akira Inoue, MD, Department of Respiratory Medicine, Tohoku University Hospital 1-1, Seiryomachi, Aobaku, Sendai, Japan, and Dr. YoungChulKim, MD, Lung cancer clinic, Pulmonary Medicine, Chonnam National University Medical School, Hwasun Hospital, Jeollanam-do, South Korea, for providing the data of their patients. We thank Dr. Kevin Shiue, MD, Indiana University School of Medicine, for English language editing. This study was supported by National Natural Science Foundation of China (No. 81472196).

\section{CONFLICTS OF INTEREST}

All authors have declared no conflicts of interest.

\section{REFERENCES}

1. Wu YL, Zhong WZ, Li LY, Zhang XT, Zhang L, Zhou CC, Liu W, Jiang B, Mu XL, Lin JY, Zhou Q, Xu CR, Wang Z, et al. Epidermal growth factor receptor mutations and their correlation with gefitinib therapy in patients with nonsmall cell lung cancer: a meta-analysis based on updated individual patient data from six medical centers in mainland China. J Thorac Oncol. 2007; 2:430-439.

2. Pao W, Girard N. New driver mutations in non-small-cell lung cancer. Lancet Oncol. 2011; 12:175-180.

3. Hata A, Katakami N, Yoshioka H, Kunimasa K, Fujita S, Kaji R, Notohara K, Imai Y, Tachikawa R, Tomii K,
Korogi Y, Iwasaku M, Nishiyama A, et al. How sensitive are epidermal growth factor receptor-tyrosine kinase inhibitors for squamous cell carcinoma of the lung harboring EGFR gene-sensitive mutations? J Thorac Oncol. 2013; 8:89-95.

4. Fang W, Zhang J, Liang W, Huang Y, Yan Y, Wu X, Hu Z, Ma Y, Zhao H, Zhao Y, Yang Y, Xue C, Zhang J, et al. Efficacy of epidermal growth factor receptor-tyrosine kinase inhibitors for Chinese patients with squamous cell carcinoma of lung harboring EGFR mutation. J Thorac Dis. 2013; 5:585-592.

5. Duan JC, An TT, Wu MN, Yang L, Bai H, Wang ZJ, Wang YY, Zhuo ML, Zhao J, Wang SH, Wang J. [Correlation between the efficacy of epidermal growth factor receptor tyrosine kinase inhibitors and EGFR mutations in advanced squamous cell lung cancer]. [Article in Chinese]. Zhonghua Jie He He Hu Xi Za Zhi. 2012; 35:323-328.

6. Maemondo M, Inoue A, Kobayashi K, Sugawara S, Oizumi S, Isobe H, Gemma A, Harada M, Yoshizawa H, Kinoshita I, Fujita Y, Okinaga S, Hirano H, et al. Gefitinib or chemotherapy for non-small-cell lung cancer with mutated EGFR. N Engl J Med. 2010; 362:2380-2388.

7. Chou TY, Chiu CH, Li LH, Hsiao CY, Tzen CY, Chang KT, Chen YM, Perng RP, Tsai SF, Tsai CM. Mutation in the tyrosine kinase domain of epidermal growth factor receptor is a predictive and prognostic factor for gefitinib treatment in patients with non-small cell lung cancer. Clin Cancer Res. 2005; 11:3750-3757.

8. Zhang XT, Li LY, Mu XL, Cui QC, Chang XY, Song W, Wang SL, Wang MZ, Zhong W, Zhang L. The EGFR mutation and its correlation with response of gefitinib in previously treated Chinese patients with advanced nonsmall-cell lung cancer. Ann Oncol. 2005; 16:1334-1342.

9. Xu JM, Han Y, Duan HQ, Gao EM, Zhang Y, Liu XQ, Zhang JS, Toschi L, Galetta D, Azzariti A, Paradiso A. EGFR mutations and HER2/3 protein expression and clinical outcome in Chinese advanced non-small cell lung cancer patients treated with gefitinib. J Cancer Res Clin Oncol. 2009; 135:771-782.

10. Tanaka K, Hata A, Kida Y, Kaji R, Fujita S, Katakami N, Imai Y. Gefitinib for a poor performance status patient with squamous cell carcinoma of the lung harboring EGFR mutation. Intern Med. 2012; 51:659-661.

11. Schwitter M, Rodriguez R, Schneider $T$, Kluckert $T$, Brutsche M, Fruh M. Epidermal growth factor receptor mutation in a patient with squamous cell carcinoma of the lung: who should be tested? Case Rep Oncol. 2013; 6:263-268.

12. Paik PK, Varghese AM, Sima CS, Moreira AL, Ladanyi M, Kris MG, Rekhtman N. Response to erlotinib in patients with EGFR mutant advanced non-small cell lung cancers with a squamous or squamous-like component. Mol Cancer Ther. 2012; 11:2535-2540.

13. Weiss GJ, Liman AK, Allen J, Cheung PY, Kukunoor RN. Squamous Cell Carcinoma of the Lung with Metastasis to the GI Tract Associated with EGFR Exon 19 Deletion. Case Rep Med. 2013; 2013:874836. 
14. Asahina H, Yamazaki K, Kinoshita I, Sukoh N, Harada M, Yokouchi H, Ishida T, Ogura S, Kojima T, Okamoto Y, Fujita Y, Dosaka-Akita H, Isobe H, et al. A phase II trial of gefitinib as first-line therapy for advanced non-small cell lung cancer with epidermal growth factor receptor mutations. Br J Cancer. 2006; 95:998-1004.

15. Kim KS, Jeong JY, Kim YC, Na KJ, Kim YH, Ahn SJ, Baek SM, Park CS, Park CM, Kim YI, Lim SC, Park KO. Predictors of the response to gefitinib in refractory non-small cell lung cancer. Clin Cancer Res. 2005; 11:2244-2251.

16. Ichihara S, Toyooka S, Fujiwara Y, Hotta K, Shigematsu H, Tokumo M, Soh J, Asano H, Ichimura K, Aoe K, Aoe M, Kiura K, Shimizu K, et al. The impact of epidermal growth factor receptor gene status on gefitinib-treated Japanese patients with non-small-cell lung cancer. Int J Cancer. 2007; 120:1239-1247.

17. Han SW, Kim TY, Hwang PG, Jeong S, Kim J, Choi IS, Oh DY, Kim JH, Kim DW, Chung DH, Im SA, Kim YT, Lee JS, et al. Predictive and prognostic impact of epidermal growth factor receptor mutation in non-small-cell lung cancer patients treated with gefitinib. J Clin Oncol. 2005; 23:2493-2501.

18. Duan J, Wang Z, Bai H, An T, Zhuo M, Wu M, Wang Y, Yang L, Wang J. Epidermal growth factor receptor variant III mutation in Chinese patients with squamous cell cancer of the lung. Thorac Cancer. 2015; 6:319-326.

19. Baik CS, Pritchard CC, Eaton KD, Chow LQ. EGFR mutations in squamous cell lung cancer in never-smokers. J Thorac Oncol. 2013; 8:e6-7.

20. Lee Y, Shim HS, Park MS, Kim JH, Ha SJ, Kim SH, Cho BC. High EGFR gene copy number and skin rash as predictive markers for EGFR tyrosine kinase inhibitors in patients with advanced squamous cell lung carcinoma. Clin Cancer Res. 2012; 18:1760-1768.

21. Yamada K, Takayama K, Kawakami S, Saruwatari K, Morinaga R, Harada T, Aragane N, Nagata S, Kishimoto J, Nakanishi Y, Ichinose Y. Phase II trial of erlotinib for Japanese patients with previously treated non-small-cell lung cancer harboring EGFR mutations: results of Lung Oncology Group in Kyushu (LOGiK0803). Jpn J Clin Oncol. 2013; 43:629-635.

22. Tamura K, Okamoto I, Kashii T, Negoro S, Hirashima T, Kudoh S, Ichinose Y, Ebi N, Shibata K, Nishimura T, Katakami N, Sawa T, Shimizu E, et al. Multicentre prospective phase II trial of gefitinib for advanced nonsmall cell lung cancer with epidermal growth factor receptor mutations: results of the West Japan Thoracic Oncology Group trial (WJTOG0403). Br J Cancer. 2008; 98:907-914.

23. D'Addario G, Rauch D, Stupp R, Pless M, Stahel R, Mach N, Jost L, Widmer L, Tapia C, Bihl M, Mayer M, Ribi K, Lerch S, et al. Multicenter phase II trial of gefitinib first-line therapy followed by chemotherapy in advanced non-small-cell lung cancer (NSCLC): SAKK protocol 19/03. Ann Oncol. 2008; 19:739-745.

24. Pallis AG, Voutsina A, Kalikaki A, Souglakos J, Briasoulis E, Murray S, Koutsopoulos A, Tripaki M, Stathopoulos E,
Mavroudis D, Georgoulias V. 'Classical' but not 'other' mutations of EGFR kinase domain are associated with clinical outcome in gefitinib-treated patients with non-small cell lung cancer. Br J Cancer. 2007; 97:1560-1566.

25. Mu XL, Li LY, Zhang XT, Wang MZ, Feng RE, Cui QC, Zhou HS, Guo BQ. Gefitinib-sensitive mutations of the epidermal growth factor receptor tyrosine kinase domain in chinese patients with non-small cell lung cancer. Clin Cancer Res. 2005; 11:4289-4294.

26. Park SH, Ha SY, Lee JI, Lee H, Sim H, Kim YS, Hong J, Park J, Cho EK, Shin DB, Lee JH. Epidermal growth factor receptor mutations and the clinical outcome in male smokers with squamous cell carcinoma of lung. J Korean Med Sci. 2009; 24:448-452.

27. Tseng JS, Yang TY, Chen KC, Hsu KH, Chen HY, Chang GC. Retrospective study of erlotinib in patients with advanced squamous lung cancer. Lung Cancer. 2012; 77:128-133.

28. Hata A, Katakami N, Kunimasa K, Yoshioka H, Fujita S, Kaji R, Tachikawa R, Tomii K, Imai Y, Iwasaku M, Ishida T. Erlotinib for pretreated squamous cell carcinoma of the lung in Japanese patients. Jpn J Clin Oncol. 2011; 41:1366-1372.

29. Berzinec P, Hlinkova K, Copakova L, Konecny M, Zavodna K, Cerna M, Culagova M, Chowaniecova G, Babal P. EGFR mutations in squamous NSCLC-Prevalence and treatment results with EGFR tyrosine kinase inhibitors (TKIs) in patients from western Slovakia. Lung Cancer. 2012; 77:S21.

30. Rooney M, Devarakonda S, Govindan R. Genomics of squamous cell lung cancer. Oncologist. 2013; 18:707-716.

31. Kang JU, Koo SH, Kwon KC, Park JW, Kim JM. Identification of novel candidate target genes, including EPHB3, MASP1 and SST at 3q26.2-q29 in squamous cell carcinoma of the lung. BMC Cancer. 2009; 9:237.

32. Herbst RS, Heymach JV, Lippman SM. Lung cancer. N Engl J Med. 2008; 359:1367-1380.

33. Dmitriev AA, Kashuba VI, Haraldson K, Senchenko VN, Pavlova TV, Kudryavtseva AV, Anedchenko EA, Krasnov GS, Pronina IV, Loginov VI, Kondratieva TT, Kazubskaya TP, Braga EA, et al. Genetic and epigenetic analysis of non-small cell lung cancer with NotImicroarrays. Epigenetics. 2012; 7:502-513.

34. Yonesaka K, Zejnullahu K, Okamoto I, Satoh T, Cappuzzo F, Souglakos J, Ercan D, Rogers A, Roncalli M, Takeda M, Fujisaka Y, Philips J, Shimizu T, et al. Activation of ERBB2 signaling causes resistance to the EGFR-directed therapeutic antibody cetuximab. Sci Transl Med. 2011; 3:99ra86.

35. Rekhtman N, Paik PK, Arcila ME, Tafe LJ, Oxnard GR, Moreira AL, Travis WD, Zakowski MF, Kris MG, Ladanyi M. Clarifying the spectrum of driver oncogene mutations in biomarker-verified squamous carcinoma of lung: lack of EGFR/KRAS and presence of PIK3CA/AKT1 mutations. Clin Cancer Res. 2012; 18:1167-1176. 
36. Cancer Genome Atlas Research Network. Comprehensive genomic characterization of squamous cell lung cancers. Nature. 2012; 489:519-525.

37. Marchetti A, Martella C, Felicioni L, Barassi F, Salvatore S, Chella A, Camplese PP, Iarussi T, Mucilli F, Mezzetti A, Cuccurullo F, Sacco R, Buttitta F. EGFR mutations in nonsmall-cell lung cancer: analysis of a large series of cases and development of a rapid and sensitive method for diagnostic screening with potential implications on pharmacologic treatment. J Clin Oncol. 2005; 23:857-865.
38. Forbes SA, Bhamra G, Bamford S, Dawson E, Kok C, Clements J, Menzies A, Teague JW, Futreal PA, Stratton MR. The Catalogue of Somatic Mutations in Cancer (COSMIC). Curr Protoc Hum Genet. 2008; Chapter 10:Unit 1011. 